\title{
T-2 Toxin-Induced Thymic Apoptosis Appears to Be Independent of Endogenouse TNF- $\alpha$ and Glucocorticoid in Vivo in Mice
}

\author{
M. Nagase ${ }^{1)}$, Z. Islam $^{1)}$, M. M. Alam ${ }^{1)}$, T. Yoshizawa ${ }^{2)}$ \\ and N. Sakato ${ }^{1)}$
}

\begin{abstract}
We investigated whether endogenous glucocorticoid and/or tumor necrosis factor- $\alpha$ (TNF- $\alpha$ ) are involved in T-2 toxin (T-2)-induced apoptosis by using adrenalectomized mice and anti-TNF- $\alpha$ antibody-injected mice. The magnitude of DNA fragmentation found in T-2-treated-adrenalectomized mice was similar to sham-operated T-2-injected group. Agarose gel electrophoresis showed that thymocytes from mice treated with T-2 alone and those from mice treated with T-2 together with anti-TNF- $\alpha$ antibody exhibited a similar pattern of DNA fragmentation. LPS-induced DNA fragmentation was markedly inhibited by the anti-TNF- $\alpha$ antibody. Taken together, T-2-induced thymic apoptosis appears to be independent of endogenous TNF- $\alpha$ and glucocorticoid in vivo in mice.
\end{abstract}

Key words : T-2 toxin, thymocyte, apoptosis, tumor necrosis factor- $\alpha$, glucocorticoid

\section{Introduction}

T-2 toxin (T-2) is a trichothecene mycotoxin principally produced by Fusarium species. $\mathrm{T}-2$ has been detected in a great number of field crops, and causes several outbreaks of mycotoxicosis in human and animals. ${ }^{1)} \quad$ Although it is known that T-2 exhibits profound immunosuppressive effects, the operating mechanism of the toxicity remains unclear. Recently, we indicated that apoptosis appeared to be involved in the thymic atrophy induced by $\mathrm{T}-2 .^{2,3)}$ We show here that $\mathrm{T}-2$-induced thymic apoptosis appears to be independent of endogenous tumor necrosis factor- $\alpha$ (TNF- $\alpha$ ) and glucocorticoid in vivo in mice.

\section{Materials and Methods}

T-2 was prepared and purified in the laboratory of Dr.Yoshizawa, Kagawa University. The purity of these mycotoxins was over $98 \%$ by gas-liquid chromatography. Cycloheximide (CHX) and dimethylsulfoxide (DMSO) were purchased from Wako Pure Chemical Ind. Ltd. (Osaka, Japan). Lipopolysuccharide (LPS, E. coli O111: B4) was purchased from Sigma Chemical Co. (St. Louis, MO). Rat monoclonal anti-mouse TNF- $\alpha$ antibody was purchased from Upstate Biotechnology Inc. (Lake Placid, NY). Female BALB/c mice and

\footnotetext{
${ }^{1)}$ Department of Life Sciences, and ${ }^{2)}$ Department of Biochemistry and Food Science, Faculty of Agriculture, Kagawa University, 2393 Ikenobe, Miki, Kagawa 761-0795, Japan Fax: +81878913021
} 
adrenalectomized female BALB/c mice of 4-weeks of age were purchased from Japan SLC Inc. (Hamamatsu, Japan). T-2 and DMSO (166 $\mu \mathrm{l} / \mathrm{kg}$ : vehicle control) were injected intraperitoneally (ip) into female BALB/c and adrenalectomized mice of $34 \pm 2$ days old. DNA fragmentation in the thymocytes and percentage of thymic apoptotic cells, hallmarks of apoptosis, were detected by agarose gel electrophoresis and diphenylamine colorimetric method, respectively., ${ }^{4,5}$

\section{Results and Discussion}

The magnitude of the DNA fragmentation found in T-2-treated-adrenalectomized mice was similar to sham-operated T-2 injected group (Fig. 1). Thus, it is suggested that T-2induced thymic apoptosis occurs through a process which is independent of the glucocorticoid pathway. Next, we examined whether endogenous TNF is involved in the T-2triggered apoptosis by administering a monoclonal antibody to TNF- $\alpha$ ( $3 \mathrm{mg} / \mathrm{kg}$, ip) into animals along with T-2. As shown in Fig. 2, agarose gel electrophoresis showed that

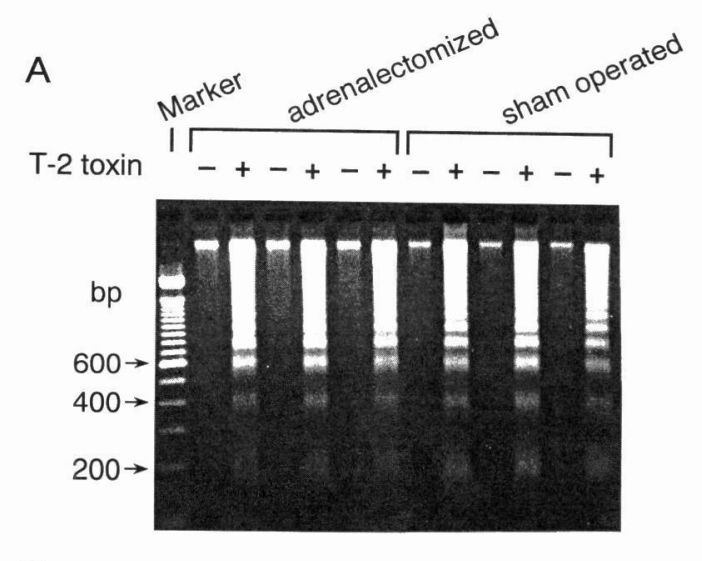

$\mathrm{B}$

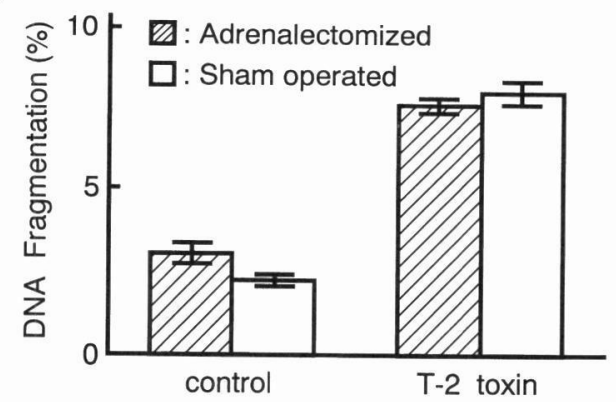

Fig. 1 Effect of Adrenalectomy on Thymic Apoptosis by T-2.

[A] : Agarose gel electrophoretic patterns of individual murine thymic DNA isolated either from vehicle-treated adrenalectomized mice, or from adrenalectomized mice treated wiht T-2 toxin, or from vehicle-treated sham-operated mice, or from sham-operated mice treated with T-2 toxin. $(+)$ : T-2 toxin treated; $(-)$ : vehicle treated. Molecular size markers are shown on the left. [B] : DNA fragmentation of the thymus from mice used in $[\mathrm{A}]$ was quantitated by the diphenylamine methed. Values shows are means \pm SEM. Results are representative of three separate experiments. 

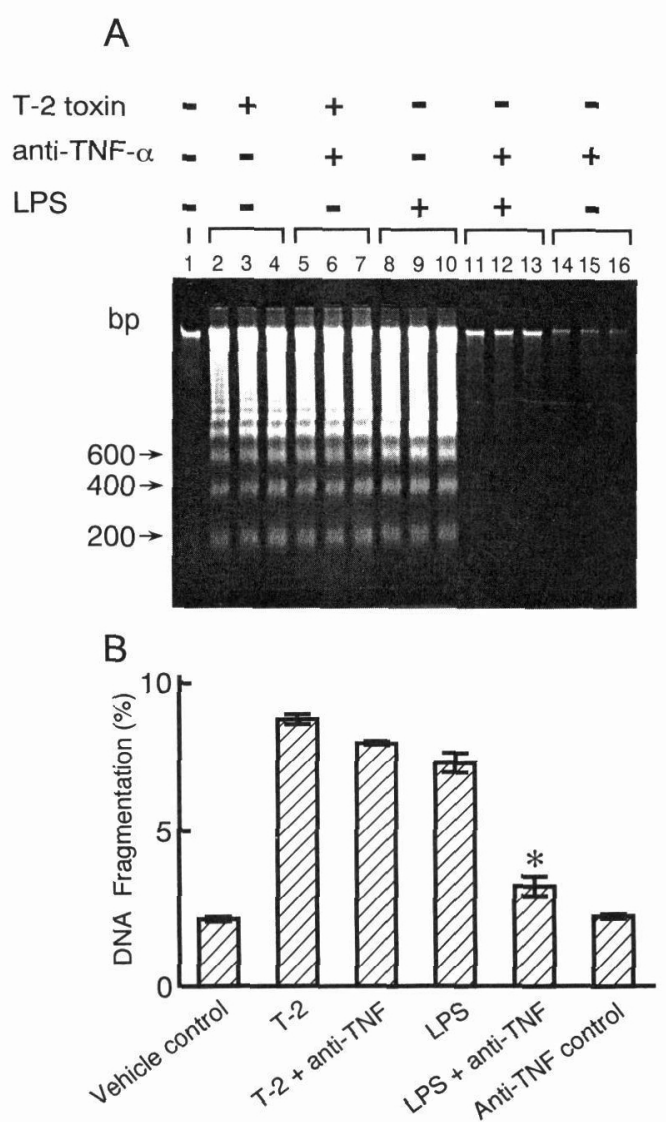

Fig. 2 Effect of Anti-TNF- $\alpha$ Antibody on T-2-induced Thymic Apoptosis in vivo.

[A] : Agarose gel electrophoretic patterns of individual murine thymic DNA either from vehicletreated mouse (lane 1), T-2 toxin-treated mice (lanes 2, 3, 4), mice injected ip with T-2 toxin along with $3 \mathrm{mg} / \mathrm{kg}$ of anti-TNF- $\alpha$ (tumor necrosis factor- $\alpha$ ) antibody (ip, $5 \mathrm{~min}$ after T-2 toxin injection) (lanes 5, 6, 7), mice injected ip with $3 \mathrm{mg} / \mathrm{kg}$ LPS (lipopolysaccharide) alone (lanes 8, 9, 10), mice injected ip with LPS ( $3 \mathrm{mg} / \mathrm{kg}$ ) along with $3 \mathrm{mg} / \mathrm{kg}$ anti-TNF- $\alpha$ antibody (ip, $5 \mathrm{~min}$ after LPS injection) (lanes 11, 12,13), or mice injected ip with same amount of anti-TNF- $\alpha$ antibody alone as another control (lanes 14, 15, 16). [B]: DNA fragmentation of the thymus from mice in $[A]$ was quantitated by the diphenylamine method. Values shown are means \pm SEM. ${ }^{*} p<0.01$ vs. LPSinjected group. Results are representative of three separate experiments.

thymocytes from mice treated with T-2 alone (lanes $2,3,4)$ and those from mice treated with T-2 together with anti-TNF- $\alpha$ antibody (lanes $5,6,7$ ) exhibited a similar pattern of DNA fragmentation. Lipopolysaccharide (LPS, $3 \mathrm{mg} / \mathrm{kg}$, ip ; positive contol)-induced DNA fragmentation (lanes 11, 12, 13) was inhibited by the anti-TNF- $\alpha$ antibody (lanes 14, 15, 16). Thus, the endogenous TNF does sot seem to be involved in the pathway leading to the thymic apoptosis induced by T-2 in vivo. CHX inhibits apoptosis by impairing de novo protein synthesis. ${ }^{6)}$ To examine whether T-2 toxin-induced apoptosis was dependent on de novo protein synthesis, a group of mice was injected with $\mathrm{CHX}(15 \mathrm{mg} / \mathrm{kg}) 5 \mathrm{~min}$ after ip injection of T-2 toxin, and the apoptotic phenomenon in terms of the DNA fragmentation was quantitated. As shown in Fig. 3, T-2 toxin alone induced clear DNA fragmentation 


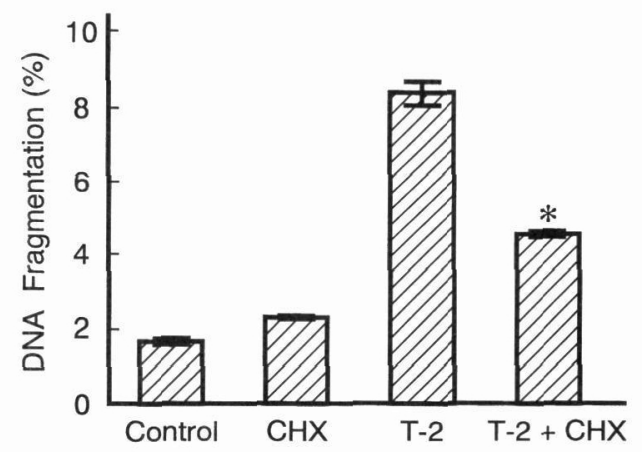

Fig. 3 Effect of Cycloheximide on T-2 Toxin-induced Thymocyte Apoptosis in vivo at 6 hr. Groups of mice, three mice per group, were injected ip with vehicle (control), or CHX (cycloheximide, $15 \mathrm{mg} / \mathrm{kg})$, or T-2 toxin $(1.75 \mathrm{mg} / \mathrm{kg})$, or T-2 toxin along with CHX (T-2+CHX). Percentage of DNA fragmentation in each thymus was assessed by the diphenylamine colorimetric method. Values shows are means \pm SEM. ${ }^{*} p<0.01$ vs. T-2 toxin-injected group.

which was significantly inhibited by $\mathrm{CHX}$.

In this study, our significant finding is that neither endogenous glucocorticoid nor TNF$\alpha$ are the causal factors of T-2 toxin-induced thymic apoptosis (Figs. 1 and 2). This was supported by in vivo experiments using adrenalectomized mice and anti-TNF- $\alpha$ antibody treatment. Our results are consistent with those of others, ${ }^{7)}$ in that calcium channel blockerinduced thymic apoptosis in rats was independent of endogenous glucocorticoids. By contrast, it was reported that both glucocorticoid and TNF- $\alpha$ were required in bacterial LPS-induced thymic apoptosis. ${ }^{8,9}$ Furthermore, in sharp contrast to our presently reported T-2 toxin-activated apoptosis (Fig. 3), administration of anti-TNF- $\alpha$ antibody in mice completely blocked $E$. coli-induced thymocyte apoptosis. ${ }^{10)}$

The mechanism of thymic atrophy production by T-2 toxin exposure is poorly understood. Here, we found that a TNF- $\alpha$-independent pathway of apoptosis may be involved in T-2 toxin induced thymic atrophy. We have also shown that the apoptotic process in the present system might be independent of glucocorticoid. Thus, further studies are needed to answer an question as to whether T-2 toxin exposure in our experimental system also targets lymphocyte progenitors in addition to double positive thymocytes.

\section{References}

1) World Health Organization (1990) Sources and Occurrence. In WHO (ed.), Selected Mycotoxins: Ochratoxins, Trichothecnes, Ergot (Environmental Health Criteria 105). Geneva.

2) Inlam, Z., Nagase, M., Yoshizawa, T., Yamauchi, K. and Sakato, N. (1998) T-2 toxin induces thymic apoptosis in vivo mice. Toxicol. Appl. Pharmacol. 148, 205-214.

3) Islam, Z., Nagase, M., Ota, A., Ueda, S., Yoshizawa, T. and Sakato, N. (1998) Structure-function relationship of $\mathrm{T}-2$ toxin and its metabolites in inducing thymic apoptosis in vivo in mice. Biosci. Biotech. Biochem. 62, 1492-1497.

4) Sellins, K. S. and Cohen, J. J. (1987) Gene induction by $\gamma$-irradiation leads to DNA fragmentation in lymphocytes. J. Immunol. 139, 3199-3206.

5) Burton, K. (1956) A study of the conditions and mechanism of the diphenylamine reaction for the colorimetric estimation of deoxyribonucleic acid. Biochem. J. 62, 315-323. 
6) Cohen, J. J. and Duke, R. C. (1984) Glucocorticoid activation of a calcium-dependent endonuclease in thymocyte nuclei leads to cell death. J. Immunol. 132, 38-42.

7) Balakumaran, A., Campbell, G. A. and Moslen, M. T. (1996) Calcium channel blockers induce thymic apoptosis in vivo in rats. Toxicol. Appl. Pharmacol. 139, 122-127.

8) Zhang, Y. H., Takahashi, K., Jiang, G. Z., Kawai M., Fukada M. and Yokochi T. (1993) In vivo induction of apoptosis (programmed cell death) in mouse thymus by administration of lipopolysaccharide. Infect. Immun. 61, 5044-5048.

9) Kato, Y., Morikawa, A., Sugiyama, T., Koido, N., Jiang, G. Z., Takahashi, K. and Yokochi, T. (1995) Role of tumor necrosis factor-alpha and glucocorticoid on lipopolysaccharide LPSJ-induced apoptosis of thymocytes. FEMS Immunol. Med. Microbiol. 12, 195-204.

10) Wang, S. D., Huang, K. J., Lin, Y. S. and Lei H. Y. (1994) Sepsis-induced apoptosis of the thymocytes in mice. J. Immunol. 152, 5014-5021. 